\title{
Prepectoral implant reconstruction in the setting of post-mastectomy radiation
}

\author{
Francis D. Graziano, Paul L. Shay, Paymon Sanati-Mehrizy, Hani Sbitany \\ Division of Plastic and Reconstructive Surgery, Icahn School of Medicine at Mount Sinai, New York, NY, USA \\ Contributions: (I) Conception and design: All authors; (II) Administrative support: None; (III) Provision of study materials or patients: All authors; \\ (IV) Collection and assembly of data: All authors; (V) Data analysis and interpretation: All authors; (VI) Manuscript writing: All authors; (VII) Final \\ approval of manuscript: All authors. \\ Correspondence to: Hani Sbitany, MD, FACS. Associate Professor, Division of Plastic and Reconstructive, Icahn School of Medicine at Mount Sinai, \\ 425 W $59^{\text {th }}$ St., $7^{\text {th }}$ floor, New York, NY 10019, USA. Email: hani.sbitany@mountsinai.org.
}

\begin{abstract}
Prepectoral breast reconstruction after mastectomy is a more commonly performed technique in recent years due to its numerous advantages over subpectoral breast reconstruction. This study reviews the current state of clinical outcomes for patients undergoing postmastectomy radiation therapy (PMRT) after prepectoral breast reconstruction. A comprehensive search of the literature was performed using the Preferred Reporting Items for Systematic Review and Meta-Analyses guidelines to identify all relevant studies. Outcome measures included demographics, mean follow-up, and complication measures. Three studies for a total of 175 breasts were identified. Average age was 49.3 years and BMI was $27.7 \mathrm{~kg} / \mathrm{m}^{2}$. Mean follow up was 18.1 months. A total of 3 (1.7\%) hematomas and 4 (2\%) seromas were reported. Surgical site infection was the most common complication reported with an overall reported 32 breasts with infections (18\%). A total of $9(5.1 \%)$ cases of wound dehiscence were reported. Mastectomy flap necrosis was found in $10(5.7 \%)$ breasts. A total of $22(12.6 \%)$ tissue expanders or implants required explantation. The review of the literature suggests that prepectoral breast reconstruction with acellular dermal matrices in the setting of post mastectomy radiation therapy is a safe and successful surgical option resulting in excellent clinical outcomes. Furthermore, there may be a reduction of capsular contracture and implant migration in this setting, relative to traditional submuscular techniques with PMRT.
\end{abstract}

Keywords: Prepectoral; radiation; breast reconstruction; prosthesis

Submitted Jan 26, 2020. Accepted for publication Mar 16, 2020.

doi: $10.21037 / \mathrm{gs} .2020 .03 .33$

View this article at: http://dx.doi.org/10.21037/gs.2020.03.33

\section{Introduction}

In the United States, approximately $80 \%$ of all breast reconstructions after mastectomy are implantbased reconstruction (1). Traditionally, implant-based reconstruction has been performed by placing the implant in a subpectoral position with partial or complete muscle coverage. However, the recent development of acellular dermal matrices (ADMs) offer an alternate for implant support and coverage in both dual-plane and the prepectoral plane for appropriate candidates (2). Studies have demonstrated the ability of ADMs to allow for safe prepectoral breast reconstruction with low morbidity rates, while supporting implants and potentially reducing rates of capsular contracture (3-5).

Prepectoral breast reconstruction offers several advantages over submuscular and dual-plane breast reconstruction for suitable patients. Patients report decreased postoperative pain, elimination of animation of deformity, decreased operative times and high patient satisfaction rates (6). These advantages are directly related 
to leaving the pectoralis muscle in its native anatomic position. Moreover, prepectoral breast reconstruction allows for precise control of the borders of the entire implant pocket with $\mathrm{ADM}$, which when coupled with nipple sparing mastectomy, result in excellent and precise aesthetic outcomes.

Adjuvant radiation therapy is routine in the oncologic treatment of mastectomy patients with lymph node-positive breast cancer and has been found to reduce the risk of recurrence and improves overall survival (7). Therefore it is important to assess success and complication rates of breast reconstructive techniques in the setting of post mastectomy radiation therapy. Postmastectomy radiation therapy (PMRT) has been shown to increase the risk of complications in prosthetic reconstruction and negatively impacts cosmetic outcomes, which is largely due to the microvascular damage and fibrosis of the breast soft-tissue envelope $(8,9)$.

Prior studies have demonstrated that ADMs can be effective in the setting of breast radiation therapy, with some studies suggesting a protective effect of ADM against implant extrusion in dual-plane reconstruction relative to complete submuscular reconstruction $(10,11)$. However, data on PMRT following prepectoral breast reconstruction, where the ADM provides the entire soft tissue envelope, is limited. The aim of this study was to systematically review the literature assessing outcomes of prepectoral implantbased reconstruction in the setting of post mastectomy radiation therapy.

\section{Methods}

The PubMed database was searched to identify all relevant articles with the following search strategy: ((prepectoral) AND radiation) AND breast reconstruction. Search results were limited to studies in the last 10 years. No additional filters were used. The search was in accordance with the Preferred Reporting Items for Systematic Review and Meta-analysis guidelines (Figure 1) (12).

The title and abstract of each retrieved publication were screened by an independent review based on the following inclusion criteria: (I) the study reported the use of prepectoral breast reconstruction in the setting of post mastectomy radiation; (II) follow up and complication data was reported; (III) article was in English. For studies in which only a subpopulation of the criteria were met, we included only the results of the subpopulation. No additional exclusion criteria were used. Data from each article were extracted, including patient demographics, average follow up, outcomes, and complications.

\section{Results}

A total of 23 abstracts were identified, of which four studies were reviewed and screened for inclusion criteria, and three studies were included in the analysis (Figure 1). A total of 175 breasts were reported, with an average patient age of 49.3 years. Three patients $(1.7 \%)$ were diabetic and three patients $(1.7 \%)$ were active smokers. Overall average BMI across all three studies was $27.7 \mathrm{~kg} / \mathrm{m}^{2}$. Overall weighted mean follow-up was 18.1 months. Patient demographic information is summarized in Table 1.

Complication data were collected and summarized in Table 2. A total of $3(1.7 \%)$ hematomas and $4(2 \%)$ seromas were reported. Surgical site infection was the most common complication reported with an overall reported 32 breasts with infections (18\%). A total of $9(5.1 \%)$ cases of wound dehiscence were reported. Mastectomy flap necrosis was found in $10(5.7 \%)$ breasts. A total of $22(12.6 \%)$ tissue expanders or implants required explantation. Lastly, two of the three studies reported capsular contracture rates, with a total of $23(13.1 \%)$ cases of capsular contracture in the follow up period.

\section{Discussion}

In recent years, prepectoral breast reconstruction has become more routinely performed. Prepectoral reconstruction offers the advantages of leaving the pectoralis muscle in its anatomic position and is associated with the elimination of animation deformity, decreased postoperative pain, and predictable aesthetic outcomes. Post mastectomy radiation therapy is a frequent oncologic treatment, and therefore it is important to assess the success and complication rates of prepectoral breast reconstruction in the setting of post mastectomy radiation therapy. The aim of this study was to review the literature for studies assessing outcomes in patients who underwent prepectoral breast reconstruction in the setting of PMRT.

Our study identified three studies that analyzed outcomes, complications and follow-up in patients, and thus matched inclusion criteria (13-15). One of the main concerns of using PMRT is the propensity for increasing complications. Most notably, the concern with PMRT is for higher rates of prosthesis explantation and capsular contracture, regardless of reconstructive method used. In the studies analyzed, 


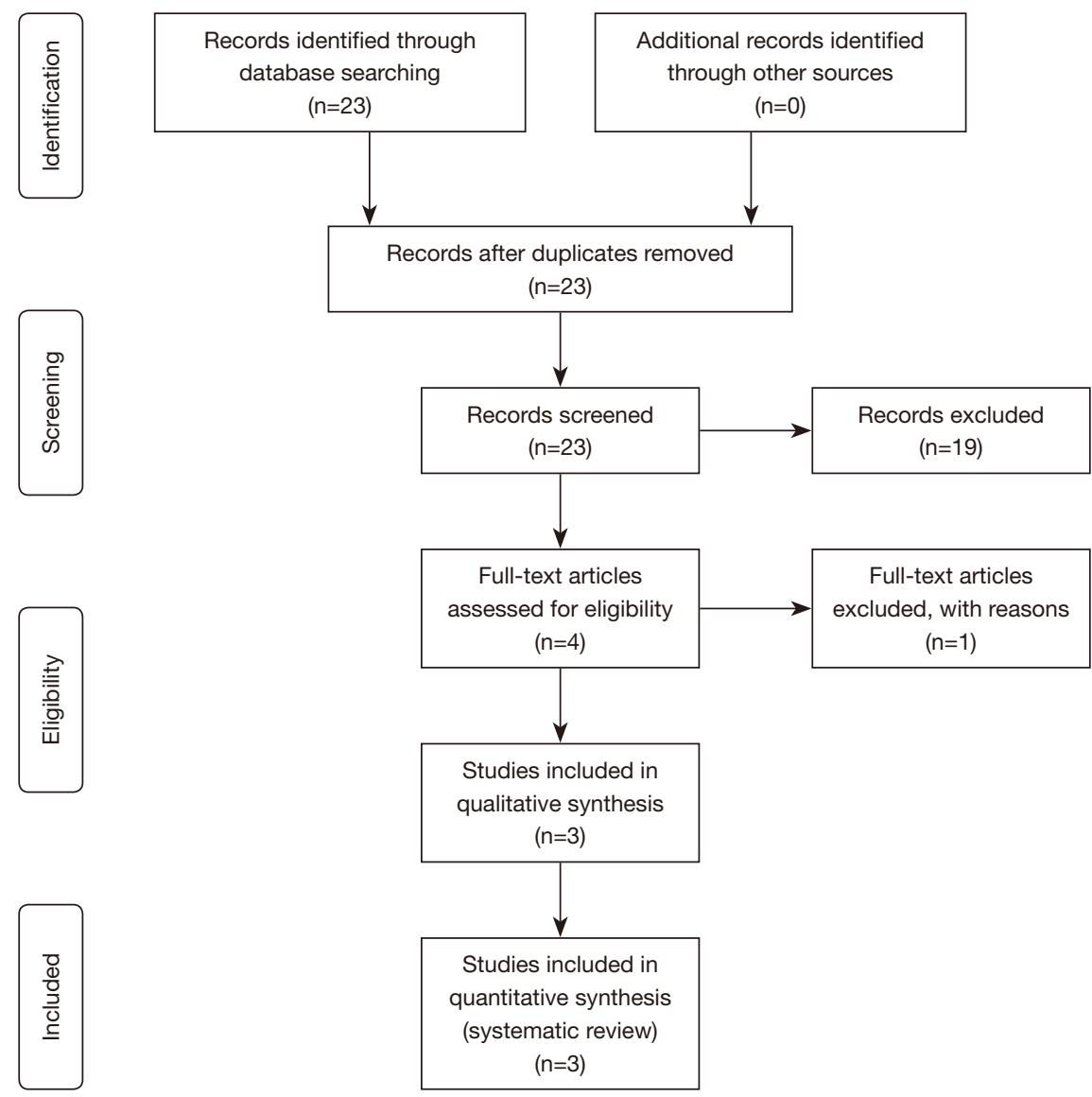

Figure 1 Diagram depicting the flow for study selection through the different phases of citation review, in accordance with the Preferred Reporting Items for Systematic Review and Meta-Analyses strategy.

Table 1 Patient demographics among prepectoral breast reconstruction patients undergoing post-mastectomy radiation therapy (adjuvant radiation therapy)

\begin{tabular}{|c|c|c|c|c|c|c|c|}
\hline Study & No. pts & No. breasts & Average age & Diabetes & Active Smoking & $\mathrm{BMI}\left(\mathrm{kg} / \mathrm{m}^{2}\right)$ & Mean follow-up (months) \\
\hline Elswick et al. & 54 & 93 & 48 & 0 & 0 & 27.2 & 19 \\
\hline Sinnott et al. & 45 & 56 & 52 & 2 & 2 & 30 & 20.6 \\
\hline Total/weighted average (\%) & - & 175 & 49.3 & $3(1.7)$ & $3(1.7)$ & 27.7 & 18.1 \\
\hline
\end{tabular}

NR, not reported.

$12.5 \%$ of prostheses required explanation and $13.1 \%$ of cases of capsular contracture were seen in the follow up period.

Studies by Sbitany et al. and Sinnott et al. compared their prepectoral cohort to subpectoral breast reconstruction cohorts undergoing PMRT, and found there was no significant difference in wound dehiscence or prosthesis explanation rates between the prepectoral and submuscular cohorts $(13,15)$. Moreover, Sinnott et al. found that the contracture rates were three times higher for the subpectoral patients following PMRT than for the prepectoral patients following PMRT $(\mathrm{P}<0.05)$ (15). These findings suggest that the complication rates between the prepectoral and subpectoral implant reconstruction are similar, and there 
Table 2 Complication rates among prepectoral patients undergoing post mastectomy radiation therapy (adjuvant radiation therapy)

\begin{tabular}{lcccccccc}
\hline Study & No. breasts & Hematoma & Seroma & SSI & Dehiscence & Mastectomy flap necrosis & Explantation & Capsular contracture \\
\hline Sbitany et al. & 26 & $2(7.6 \%)$ & $2(7.6 \%)$ & $11(42 \%)$ & $4(15 \%)$ & $4(15 \%)$ & $4(15 \%)$ & NR \\
Elswick et al. & 93 & $1(1 \%)$ & $1(2 \%)$ & $9(9.6 \%)$ & $1(1 \%)$ & $1(1 \%)$ & $1(1 \%)$ & $1(1 \%)$ \\
Sinnott et al. & 56 & $0(0 \%)$ & $1(1.7 \%)$ & $12(21 \%)$ & $4(7.1 \%)$ & $5(8.9 \%)$ & $17(30 \%)$ & $22(39 \%)$ \\
Overall & 175 & $3(1.7 \%)$ & $4(2 \%)$ & $32(18 \%)$ & $9(5.1 \%)$ & $10(5.7 \%)$ & $22(12.5 \%)$ & $23(13.1 \%)$ \\
\hline
\end{tabular}

SSI, surgical site infection; NR, not reported.

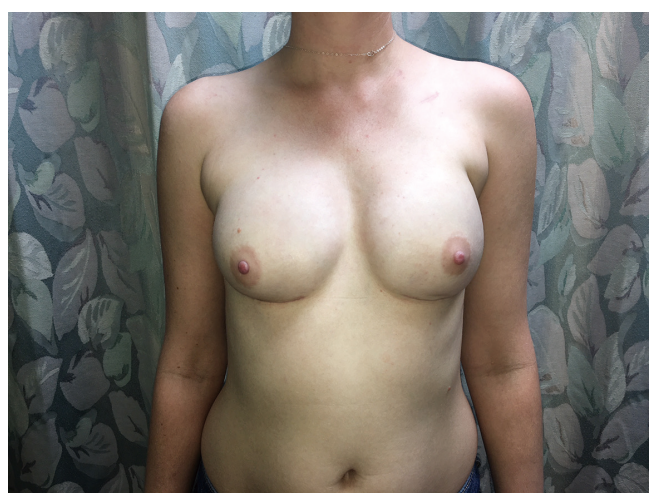

Figure 2 A 37-year-old female patient, 1 year postoperative, following completion of bilateral nipple sparing mastectomies, bilateral prepectoral reconstruction, and left postmastectomy radiation therapy; the left radiated skin envelope is tighter, but there is no migration of the implant due to the prepectoral placement of the prosthesis.

is the benefit of a potential protective effect of ADMs in prepectoral reconstruction against capsular contracture.

This data suggests that having pectoralis muscle coverage over the prosthesis in the setting of radiation does not offer improved protection of the device. The soft tissue damage induced by radiation results in pectoralis fibrosis and tightening, thereby pulling the implant superiorly and laterally towards the origin of the pectoralis on the humerus. The use of acellular dermal in dual-plane reconstruction has previously been demonstrated to be protective against capsule formation and implant extrusion in the setting of whole breast radiation $(10,11)$.

Several criteria must be met before considering a patient for prepectoral breast reconstruction. First is patient selection; for best results, patients should be nonobese and non-smokers. Second, the mastectomy flap envelope must be well perfused, which can be confirmed with intraoperative angiography. Lastly, from an oncologic perspective, the tumor should be more than $0.5 \mathrm{~cm}$ from the pectoralis muscle (16). Any patient with a deep tumor within $0.5 \mathrm{~cm}$ of the pectoralis major muscle, palpable axillary adenopathy, inflammatory breast cancer, or perfused skin flaps following mastectomy is a poor prepectoral candidate, and delayed reconstruction should be considered.

If a patient is deemed a good candidate for prepectoral breast reconstruction, the senior author promotes the prepectoral technique as the primary procedure for reconstruction even with plans for post mastectomy radiation therapy planned (Figure 2). The senior author has previously described his technique for prepectoral breast reconstruction (3). An important consideration for prepectoral breast reconstruction in the setting of PMRT is the use of counter incisions for the different operations on each patient. Regardless of the incision location used for the mastectomy and tissue expander placement, the incision for the second stage surgery for implant placement after radiation therapy should be performed through a new incision. The original incision consists of radiated scar tissue that is devascularized, therefore a new incision should be created. This technique helps decrease wound dehiscence rates in breasts that have undergone PMRT. Another consideration is the role of fat grafting in prepectoral reconstruction patients that undergo radiation. In prepectoral patients, fat grafting becomes more critical due to the ability of fat to reduce the effects of radiation fibrosis on the overlying mastectomy flaps and soft tissue envelope (17).

A consensus has not been reached regarding optimal timing for exchange of tissue expanders to permanent implants in patients undergoing 2-stage expanderimplant reconstruction following completion of PMRT. A study by Peled et al. compared patients who underwent tissue expander to implant exchange within 6 months of post mastectomy radiation therapy with patients that had exchange 6 months after post mastectomy radiation therapy (18). The authors found that there were more 
implant failures in the cohort that had exchange within 6 months of PMRT completion. This would suggest that waiting longer than 6 months for second stage exchange of tissue expander may decrease complication rates, however more research is needed to understand the most ideal timing for exchange. Furthermore, much of the decision for timing of the exchange must be made on a case by case basis, depending on the patient's healing after PMRT, and the dosage of radiation delivery.

There are several limitations of this review. First is the relatively small sample size of the patients that were identified that underwent both prepectoral reconstruction and PMRT. The average follow-up among the included studies was 18.1 months. Some may argue this is too short of a time to properly assess certain complications such as capsular contracture, especially in the irradiated patient.

Current literature suggests that prepectoral breast reconstruction with ADMs in the setting of post mastectomy radiation therapy is safe for appropriate candidates. Further high-quality research is needed for prepectoral reconstruction, not only for evaluating safety outcomes, but also for aesthetic and patient-centered outcomes.

\section{Acknowledgments}

Funding: None.

\section{Footnote}

Provenance and Peer Review: This article was commissioned by the Guest Editors (Charles E Butler, Carrie Chu, and Margaret Roubaud) for the series "New Frontiers in Breast Reconstruction" published in Gland Surgery. The article was sent for external peer review organized by the Guest Editors and the editorial office.

Conflicts of Interest: All authors have completed the ICMJE uniform disclosure form (available at http://dx.doi. org/10.21037/gs.2020.03.33). Hani Sbitany serves as an editorial board member of Gland Surgery from Feb 2019 Jan 2021, and a consultant for Allergan, Inc. He received no compensation or support for this study. The remaining authors have no disclosures related to the content of this article.

Ethical Statement: The authors are accountable for all aspects of the work in ensuring that questions related to the accuracy or integrity of any part of the work are appropriately investigated and resolved.

Open Access Statement: This is an Open Access article distributed in accordance with the Creative Commons Attribution-NonCommercial-NoDerivs 4.0 International License (CC BY-NC-ND 4.0), which permits the noncommercial replication and distribution of the article with the strict proviso that no changes or edits are made and the original work is properly cited (including links to both the formal publication through the relevant DOI and the license). See: https://creativecommons.org/licenses/by-nc-nd/4.0/.

\section{References}

1. American Society of Plastic Surgeons. Plastic Surgery Statistics Report 2016. Retrieved 11 February 2018. Available online: https://www.plastic/surgery.org/news/ plastic-surgery-statistics

2. Sbitany H, Sandeen SN, Amalfi AN, et al. Acellular dermis-assisted prosthetic breast reconstruction versus complete submuscular coverage: a head-tohead comparison of outcomes. Plast Reconstr Surg 2009;124:1735-40.

3. Sbitany H, Piper M, Lentz R. Prepectoral Breast Reconstruction: A Safe Alternative to Submuscular Prosthetic Reconstruction following Nipple-Sparing Mastectomy. Plast Reconstr Surg 2017;140:432-43.

4. Sigalove S. Options in Acellular Dermal Matrix-Device Assembly. Plast Reconstr Surg 2017;140:39S-42S.

5. Basu CB, Jeffers L. The role of acellular dermal matrices in capsular contracture: a review of the evidence. Plast Reconstr Surg 2012;130:118S-24S.

6. Nahabedian MY, Cocilovo C. Two-Stage Prosthetic Breast Reconstruction: A Comparison Between Prepectoral and Partial Subpectoral Techniques. Plast Reconstr Surg 2017;140:22S-30S.

7. Recht A, Comen EA, Fine RE, et al. Postmastectomy Radiotherapy: An American Society of Clinical Oncology, American Society for Radiation Oncology, and Society of Surgical Oncology Focused Guideline Update. Pract Radiat Oncol 2016;6:e219-34.

8. Momoh AO, Ahmed R, Kelley BP, et al. A systematic review of complications of implant-based breast reconstruction with prereconstruction and postreconstruction radiotherapy. Ann Surg Oncol 2014;21:118-24.

9. Nelson JA, Disa JJ. Breast Reconstruction and 
Radiation Therapy: An Update. Plast Reconstr Surg 2017;140:60S-8S.

10. Seth AK, Hirsch EM, Fine NA, et al. Utility of acellular dermis-assisted breast reconstruction in the setting of radiation: a comparative analysis. Plast Reconstr Surg 2012;130:750-8

11. Spear SL, Seruya M, Rao SS, et al. Two-stage prosthetic breast reconstruction using AlloDerm including outcomes of different timings of radiotherapy. Plast Reconstr Surg 2012;130:1-9.

12. Liberati A, Altman DG, Tetzlaff J, et al. The PRISMA statement for reporting systematic reviews and metaanalyses of studies that evaluate health care interventions: explanation and elaboration. PLoS Med 2009;6:e1000100.

13. Sbitany H, Gomez-Sanchez C, Piper M, et al. Prepectoral Breast Reconstruction in the Setting of Postmastectomy Radiation Therapy: An Assessment of Clinical Outcomes and Benefits. Plast Reconstr Surg 2019;143:10-20.

14. Elswick SM, Harless CA, Bishop SN, et al.

Cite this article as: Graziano FD, Shay PL, Sanati-Mehrizy P, Sbitany H. Prepectoral implant reconstruction in the setting of post-mastectomy radiation. Gland Surg 2021;10(1):411-416. doi: 10.21037 /gs.2020.03.33
Prepectoral Implant-Based Breast Reconstruction with Postmastectomy Radiation Therapy. Plast Reconstr Surg 2018;142:1-12.

15. Sinnott CJ, Persing SM, Pronovost M, et al. Impact of Postmastectomy Radiation Therapy in Prepectoral Versus Subpectoral Implant-Based Breast Reconstruction. Ann Surg Oncol 2018;25:2899-908.

16. Yang JY, Kim CW, Lee JW, et al. Considerations for patient selection: Prepectoral versus subpectoral implant-based breast reconstruction. Arch Plast Surg 2019;46:550-7.

17. Garza RM, Paik KJ, Chung MT, et al. Studies in fat grafting: Part III. Fat grafting irradiated tissue--improved skin quality and decreased fat graft retention. Plast Reconstr Surg 2014;134:249-57.

18. Peled AW, Foster RD, Esserman LJ, et al. Increasing the time to expander-implant exchange after postmastectomy radiation therapy reduces expander-implant failure. Plast Reconstr Surg 2012;130:503-9. 